Research Article

\title{
Effect of Hydration Heat Inhibitor on Thermal Stress of Hydraulic Structures with Different Thicknesses
}

\author{
Wenqiang Xu $\mathbb{D}^{1},{ }^{1}$ Sheng Qiang ${ }^{1},{ }^{1}$ Zhengkai Hu $\mathbb{D},{ }^{2}$ Bingyong Ding $\mathbb{D}^{2}$ \\ and Bingyong Yang ${ }^{3}{ }^{3}$
}

${ }^{1}$ College of Water Conservancy and Hydropower, Hohai University, Nanjing 210098, China

${ }^{2}$ HydroChina Huadong Engineering Corporation Limited, Hangzhou 311122, China

${ }^{3}$ Buer New Material Technology Corporation Limited, Nantong 226541, China

Correspondence should be addressed to Sheng Qiang; sqiang2118@hhu.edu.cn

Received 16 November 2019; Revised 11 July 2020; Accepted 26 August 2020; Published 10 September 2020

Academic Editor: Prinya Chindaprasirt

Copyright ( $\odot 2020$ Wenqiang Xu et al. This is an open access article distributed under the Creative Commons Attribution License, which permits unrestricted use, distribution, and reproduction in any medium, provided the original work is properly cited.

Concrete hydration heat inhibitor can inhibit the early hydration reaction of concrete and reduce the initial heat release of concrete. However, there is no in-depth research on the effect of hydration heat inhibitor on hydraulic structures with different thicknesses and constraints. In this paper, numerical simulation is used to study the change of temperature and stress field after adding hydration heat inhibitor by establishing the finite element models of tunnel lining, sluice, and gravity dam. The results show that the effect of the hydration heat inhibitors on reducing the temperature peak is inversely proportional to the thickness of the structure. A formula is put forward to evaluate their relation in this paper. When the thickness of the structure is about $6 \mathrm{~m}$, there is no peak cutting effect. For the stress field, hydration heat inhibitor can greatly reduce the thermal stress of the thin-walled structure and make the structure meet the temperature control requirements; for the medium wall thickness structure, it can reduce the internal tensile stress about $50 \%$ and the surface tensile stress about $20 \%$, and other temperature control measures are still needed to ensure that the surface tensile stress of the structure meets the requirements; for hydraulic structures with large volume and thickness, the application effect of the inhibitor has limitations, which can reduce the internal tensile stress about $30 \%$, but the tensile stress in the surface area will increase about $7 \%$ due to the increase of the internal and external temperature difference; therefore, other temperature control measures such as arranging cooling water pipe, strengthening surface insulation, and so on are needed to ensure that temperature cracks do not occur. This paper provides references and suggestions for the research and engineering application of hydration heat inhibitor.

\section{Introduction}

It is generally accepted that excessive thermal stress exceeds the tensile strength of concrete, which is the main reason for the cracking of early-stage mass concrete structure $[1,2]$. The main reasons for the thermal stress of the early-stage mass concrete can be summarized as follows: the temperature of the concrete is unevenly distributed in space, and the local temperature gradient of the concrete is large; at the same time, the temperature and mechanical properties of the concrete change greatly in time, and the structure is subject to various constraints (foundation constraints, new and old concrete contact surface constraints, etc.) which will lead to large thermal stress $[3,4]$.
The hydration heat released by the hydration reaction during concrete pouring is the most important reason for the uneven spatial and temporal distribution of temperature [5]. The different heat release rate of hydration heat and the amount of heat released have a great influence on the spatial and temporal distribution of the concrete temperature field $[6,7]$. Therefore, the temperature control measures commonly used to control hydration heat include the use of lowcalorie cement, increasing the aggregate content when mixing, controlling the temperature of concrete pouring, and cooling by water $[8,9]$.

However, in actual engineering project, it is difficult to adjust the concrete mix ratio. For small water conservancy 
projects, it is difficult to use temperature control measures such as aggregate precooling and ice mixing to control the temperature of concrete pouring due to economic factors. For thin-walled and massive concrete structures such as hydraulic tunnel linings, aqueducts, and small sluice floors, due to the large temperature gradient inside the structure and the constraints of the foundation or surrounding rocks, large thermal stresses will be generated $[10,11]$. The thickness of the structure is thin, so it is not easy to lay cooling water pipes, and the cost of measures to limit the cracks in the steel bar is high [12]. Therefore, in order to solve these problems, other temperature control measures are needed to reduce the thermal stress of early-stage concrete.

As an effective means to improve the thermal and mechanical properties of concrete, concrete admixtures have been widely used in engineering [13-15]. Commonly used concrete admixtures include water-reducing agents, retarders, air-entraining agents, etc., among which water-reducing agents can reduce the use of water and reduce the heat released by the hydration reaction [16].

As a new type of concrete admixture, the hydration heat inhibitor is prepared by acid hydrolysis of corn starch. It is used to solve the problem of temperature cracks caused by excessive thermal stress of early-stage massive concrete $[17,18]$. Related research [19] shows that the addition of hydration heat inhibitors has a significant effect on the nucleation of C-S-H, and hydration heat inhibitors reduce the main peak of the hydration reaction. However, once C-S$\mathrm{H}$ is formed, its growth will be very stable and will not be affected by the hydration heat inhibitor. Therefore, the thermal performance is that the hydration heat inhibitor inhibits the initial hydration reaction rate of the concrete and slows the hydration heat release rate; however, after pouring for some days (depending on the dosage), the strength will reach the reference value, and the total hydration reaction heat release will not change.

However, these research studies on hydration heat inhibitors only involve the mechanism, and there is little mention of the application in actual engineering project. Therefore, it is not clear what effect the hydration heat inhibitor has on the temperature field and stress field of mass concrete, and there is no clear analysis of the effect of using it in different structural thicknesses.

This paper mainly studies the influence of hydration heat inhibitor on the spatial and temporal distribution of temperature field of mass concrete with different structure thicknesses by means of numerical simulation so as to derive the change of thermal stress of structure. We analyze the simulation results to get the change law of temperature field and stress field caused by hydration heat inhibitor and verify through experiments so as to provide references and suggestions for the application of hydration heat inhibitors in engineering project.

\section{Methods and Numerical Modeling}

2.1. Research Methods. In this paper, the hydration heat inhibitor (HHC-S) is mainly studied by numerical simulation. First, the adiabatic temperature rise curves of "reference concrete (BC)" (no hydration heat inhibitor) and "inspected concrete (IC)" (addition of hydration heat inhibitor) are fitted by the experimental data of adiabatic temperature rise; after that, the models of aqueduct (structural thickness: $0.5 \mathrm{~m})$, hydraulic tunnel lining $(0.5 \mathrm{~m})$, sluice floor and pier $(1.2 \mathrm{~m})$, and part of the gravity dam $(18 \mathrm{~m})$ were established. The thermodynamic parameters of "reference concrete (BC)" and "inspected concrete (IC)" obtained by experiment are used as calculation parameters to simulate the temperature field and stress field of different models. The thermodynamic parameters of the foundation and surrounding rock adopt the parameters of related actual engineering projects, and the concrete pouring time interval and pouring sequence are simulated according to the actual construction conditions.

The thermodynamic coupling module of the general finite element analysis software ANSYS was used for simulation. In order to observe the spatial distribution characteristics of temperature and stress field of two different concrete pouring structures, the envelope diagrams of the temperature and stress field are drawn to compare the different distribution characteristics and changes of the temperature and stress field. Select the key points in the area of high temperature or easy to generate temperature cracks in the envelope diagram, draw the temperature or stress duration curve of the key points, observe the time distribution characteristics of temperature and stress, and compare the effect of the two kinds of concrete in different thickness structures. Finally, the temperature and stress field data of different thickness structures obtained by simulation are compared and analyzed, and the sensitivity of the application effect of hydration heat inhibitor to the structure thickness is obtained.

In order to verify the results of the study, an experimental study of engineering project was carried out, and the experimental object was the subway side wall. By measuring the temperature change of the central point of the subway side wall, the effect of hydration heat inhibitors applied in engineering projects was studied. At the same time, the temperature data measured by the experiment are compared with the temperature data obtained by the numerical simulation to verify the reliability of the numerical simulation study.

\subsection{Theory of Finite Element Method}

2.2.1. Algorithm of Unsteady Temperature Field. At an arbitrary point in computation domain $R$, unsteady temperature field $T(x, y, z, t)$ must meet the following control equation of heat conduction:

$$
\left(\frac{\partial^{2} T}{\partial x^{2}}\right)+\left(\frac{\partial^{2} T}{\partial y^{2}}\right)+\left(\frac{\partial^{2} T}{\partial z^{2}}\right)+\left(\frac{c \rho}{\lambda}\right)\left(\frac{\partial \theta}{\partial \tau}-\frac{\partial T}{\partial \tau}\right)=0,
$$

where $T$ is the temperature $\left({ }^{\circ} \mathrm{C}\right) ; \lambda$ is the thermal diffusivity $\left(\mathrm{kg} /\left(\mathrm{m} \cdot \mathrm{d} \cdot{ }^{\circ} \mathrm{C}\right)\right) ; \quad c$ is the specific heat capacity $\left(\mathrm{kJ} /\left(\mathrm{kg} \cdot{ }^{\circ} \mathrm{C}\right)\right) ; \rho$ is the density $\left(\mathrm{kg} / \mathrm{m}^{3}\right) ; \theta$ is the concrete adiabatic temperature $\left({ }^{\circ} \mathrm{C}\right)$; and $\tau$ is the time $(\mathrm{d})$. 

C:

Meet the third type of boundary conditions on boundary

$$
l_{x}\left(\frac{\partial T}{\partial x}\right)+l_{y}\left(\frac{\partial T}{\partial y}\right)+l_{z}\left(\frac{\partial T}{\partial z}\right)+\left(\frac{\beta}{\lambda}\right)\left(T-T_{a}\right)=0,
$$

where $\beta$ is the surface heat dissipation coefficient $\left(\mathrm{kJ} /\left(\mathrm{m}^{2} \cdot \mathrm{h} \cdot{ }^{\circ} \mathrm{C}\right)\right) ; T_{a}$ is the ambient temperature $\left({ }^{\circ} \mathrm{C}\right)$; and $l_{x}, l_{y}$, and $l_{z}$ are the direction cosine of the normal outside the boundary surface.

According to the variational principle, solving the heat conduction problem is equivalent to solving the minimum value of the following functional:

$$
I(T)=\iiint_{R}\left\{\left(\frac{1}{2}\right)\left[\left(\frac{\partial T}{\partial x}\right)^{2}+\left(\frac{\partial T}{\partial y}\right)^{2}+\left(\frac{\partial T}{\partial z}\right)^{2}\right]-\left(\frac{1}{a}\right)\left(\frac{\partial \theta}{\partial \tau}-\frac{\partial T}{\partial \tau}\right) T\right\} \mathrm{d} x \mathrm{~d} y \mathrm{~d} z+\iint_{C}\left[\left(\frac{\beta}{\lambda}\right)\left(\frac{1}{2} T^{2}-T_{a} T\right) \mathrm{d} s\right]
$$

Discretize the calculation domain $R$ into hexahedral elements. Find the derivative of equation (3) within the integral number and perform the time domain difference to obtain the recursive equation of the unstable temperature field [20]:

$$
\left([H]+\left(\frac{1}{\Delta \tau_{n}}\right)[R]\right)\left\{T_{n+1}\right\}-\left(\frac{1}{\Delta \tau_{n}}\right)[R]\left\{T_{n}\right\}+\left\{F_{n+1}\right\}=0,
$$

where $[H]$ is the heat conduction matrix, which represents the heat conduction of the region and the boundary heat exchange, $[H]$ is the m-order square matrix, and $m$ is the total number of nodes after the region is discretized; $[R]$ is the supplement matrix of heat transfer; $\left\{T_{n}\right\}$ and $\left\{T_{n+1}\right\}$ are the node temperature vectors; $\left\{F_{n+1}\right\}$ is the node temperature load vector, which represents the hydration heat of concrete and the ambient temperature; nis the iterative calculation step; and $\Delta \tau_{n}$ is the calculation time step. According to equation (4), $\left\{T_{n+1}\right\}$ can be obtained from $\left\{T_{n}\right\}$, where $[H]$ and $[R]$ are invariants in the iteration and $\left\{F_{n+1}\right\}$ is a known quantity in the iteration.

When the temperature field calculation parameters are selected properly, the temperature data simulated by the finite element method (FEM) are close to the measured data. Some scholars used FEM to simulate the temperature field of large bridge piers. The simulation results are close to the measured data, which proves the correctness of FEM to simulate the unstable temperature field of early-stage mass concrete [21].

2.2.2. Algorithm of Stress Field. The calculation area adopts the same calculation unit as the temperature field, and the overall balance equation is established according to the principle of virtual work [20].

$$
[K]\left\{\Delta \delta_{n}\right\}=\left\{\Delta P_{n}^{L}\right\}+\left\{\Delta P_{n}^{T}\right\},
$$

where $[K]$ is the overall stiffness matrix; $\left\{\Delta \delta_{n}\right\}$ is the increment of nodal displacement during $\Delta \tau_{n} ;\left\{\Delta P_{n}^{L}\right\}$ is the equivalent nodal force increment caused by external load (mainly the structure weight) during $\Delta \tau_{n}$; and $\left\{\Delta P_{n}^{T}\right\}$ is the equivalent nodal force increment caused by temperature change (using temperature field simulation results) during $\Delta \tau_{n}$.
After the displacement increment is obtained, the node stress increment is calculated by the following formula:

$$
\left\{\Delta \sigma_{n}\right\}=E_{n}[Q]^{-1}\left([B]\left\{\Delta \delta_{n}\right\}-\alpha\left[\left\{T_{n+1}\right\}-\left\{T_{n}\right\}\right]\right),
$$

where $\left\{\Delta \delta_{n}\right\}$ is the stress increment of the node; $E_{n}$ is the elastic modulus of the material in the calculation step; $E_{n}[Q]^{-1}$ is the elastic matrix; $[B]$ is the relationship matrix between displacement and strain; and $\alpha$ is the coefficient of thermal expansion.

Accumulate the incremental results of each step to obtain displacement $\left(\delta_{n}\right)$ and stress $\left(\sigma_{n}\right)$ at any time:

$$
\begin{gathered}
\delta_{n}=\sum_{i=1}^{n} \Delta \delta_{i}, \\
\sigma_{n}=\sum_{i=1}^{n} \Delta \sigma_{i} .
\end{gathered}
$$

2.3. ANSYS Numerical Simulation. ANSYS is large-scale general-purpose finite element calculation software, which has the characteristics of high calculation efficiency, accurate calculation results, and easy secondary development. Therefore, this paper uses ANSYS to numerically simulate the temperature and stress field of different thickness structures. The ANSYS simulation uses the above algorithms of temperature and stress field. The aforementioned algorithms for temperature and stress fields are used in ANSYS calculations. Some scholars use ANSYS to simulate the temperature stress of mass concrete, and the calculation results show that it is similar to the actual project [22-24]. At the same time, because the cost of ANSYS numerical simulation is relatively low, it can guide the construction of the project based on the results of the simulation [25].

In order to ensure the accuracy of ANSYS simulation results, the simulation conditions are similar to the actual construction conditions of the project. During the simulation process:

(1) The model mesh is divided into hexahedral elements. The mesh is regular and very dense.

(2) The APDL language (ANSYS Parametric Design Language) is adopted, which makes the application 
of boundary conditions and the input of calculation parameters more accurate and convenient. It especially solves the problem of elastic modulus change during stress field calculation and the incremental calculation of stress.

(3) The technology of life and death unit is used to simulate the layered pouring of concrete. The principle is as follows: set the unit that is not to be poured into a dead unit not to participate in the structural calculation. When the unit starts to be poured, it returns to the normal unit and participates in the structural calculation.

(4) In the thermal analysis, the change of material thermal conductivity, linear expansion coefficient, surface heat dissipation coefficient, and density with time or temperature is not considered.

(5) The SOILD70 element is used in thermal analysis, and the SOLID45 element is used in structural analysis.

\section{Numerical Simulation Parameters}

In order to obtain the adiabatic temperature rise curve of "reference concrete (BC)" and "inspected concrete (IC)" added with hydration heat inhibitor, an adiabatic temperature rise experiment was carried out. The concrete mix in the experiment is shown in Table 1. The temperature rise inhibitor added in the experiment is a hydration heat inhibitor (HHC-S) produced by a Wuhan company, prepared by acid hydrolysis of corn starch, and the added amount is $1 \%$ of the mass of the gel material (cement and fly ash). The obtained adiabatic temperature rise data are shown in Table 2 .

The experimental data of adiabatic temperature rise of reference concrete (BC) are fitted by double exponential formula, and the calculation formula is as follows:

$$
\theta(\tau)=35.0 *\left[1-e^{-0.714 \tau^{0.6129}}\right] .
$$

The adiabatic temperature rise curve changes greatly, so it is difficult to meet the calculation accuracy requirements by using the conventional double exponential formula, so the combined double exponential formula is adopted here:

$$
\theta(\tau)=20.0 *\left[1-e^{-0.3214 \tau^{1.1254}}\right]+14.5 *\left[1-e^{-0.0006 \tau^{3.0227}}\right]
$$

The adiabatic temperature rise fitting formula is compared with the experimental value as shown in Figure 1.

It can be seen from Figure 1 that compared with the reference concrete after adding HHC-S, the rate of heat release in the early stage of the concrete is significantly slowed down, and the temperature in the middle stage rises more evenly with time. The final temperature rise and total heat release are the same. This is because the hydration heat inhibitor will gradually dissolve in the alkaline environment of concrete and adhere to the surface of the gel material, thus affecting the nucleation of C-S-H and inhibiting the accelerated hydration of cement; at the same time, the amount of hydration heat inhibitor dissolved in the concrete is small, and the continuous dissolution and adsorption in the concrete make the hydration reaction proceed gradually and slowly release heat. Once C-S-H is formed, the growth will be very stable and not affected by the hydration heat inhibitor, so it has little effect on other thermodynamic parameters of concrete.

The basic thermodynamic parameters used in the numerical simulation are listed in Tables 3 and 4 .

In practical projects, for the tunnels, aqueducts, and sluices, the final adiabatic temperature rise of the concrete is higher, which can reach $50^{\circ} \mathrm{C}$. Therefore, in this numerical simulation, the final value of the adiabatic temperature rise will be increased, and the adiabatic temperature rise of the reference concrete $(\mathrm{BC})$ will be set to $50^{\circ} \mathrm{C}$, and the change trend will not change. The adiabatic temperature rise of the inspected concrete (IC) shall be magnified at the same time. The calculation formula of the adjusted adiabatic temperature rise is

$$
\begin{aligned}
& \text { BC: } \theta(\tau)=50.0 *\left[1-e^{-0.714 \tau^{0.6129}}\right] \\
& \text { IC: } \theta(\tau)=28.6 *\left[1-e^{-0.3214 \tau^{1.1254}}\right]+20.7 *\left[1-e^{-0.0006 \tau^{3.0227}}\right] .
\end{aligned}
$$

The tensile strength and elastic modulus of concrete are increased with time. The results show that after adding concrete inhibitor, the hydration reaction of the concrete in the early stage is inhibited, and the tensile strength and elastic modulus are relatively reduced, but in the later stage, the tensile strength and elastic modulus will be improved because the hydration reaction of concrete is more sufficient.

The concrete compressive strength and elastic modulus satisfy the following relationship [20]:

$$
E(\tau)=\frac{10^{5}}{\left(A+B / R_{c}(\tau)\right)},
$$

where $A=2.3, B=27.5 ; R_{c}(\tau)$ is the compressive strength of concrete at age $\tau, \mathrm{MPa}$; and $E(\tau)$ is the elastic modulus of concrete at age $\tau$. The tensile strength $R_{t}(\tau)$ of the corresponding age of concrete is taken as $\left(1 / 10 R_{c}(\tau)\right)$.

The compressive strength is measured by experiment, the elastic modulus of concrete at corresponding age is calculated by equation (11), and the formula of elastic modulus changing with age is obtained by fitting

$$
\begin{aligned}
& \text { BC: } E(\tau)=32.0 *\left(1-e^{-0.5821 * \tau^{0.91}}\right) \quad(\mathrm{GPa}), \\
& \mathrm{IC:} E(\tau)=32.5 *\left(1-e^{-0.4313 * \tau^{1.0386}}\right) \quad(\mathrm{GPa}) .
\end{aligned}
$$

\section{Thermal Stress Results Analysis}

Select the typical hydraulic structure, and considering the different structure thicknesses and constraints, establish the calculation model: 
TABle 1: Concrete mix ratio $\left(\mathrm{kg} / \mathrm{m}^{3}\right)$.

\begin{tabular}{lcccccccc}
\hline Concrete type & Water & Cement & Fly ash & Artificial sand & Aggregate & Water-reducing agent & Air-entraining agent & HHC-S \\
\hline BC & 118 & 246 & 82 & 609 & 1333 & 2.3 & 0.03 \\
IC & 118 & 246 & 82 & 609 & 1333 & 2.3 & 0.03 \\
\hline
\end{tabular}

TABLE 2: Test results of adiabatic temperature rise of concrete.

\begin{tabular}{lccccccccccc}
\hline Age/d & 1 & 2 & 3 & 4 & 5 & 6 & 7 & 8 & 14 & 21 & 28 \\
\hline Reference (BC) $\left({ }^{\circ} \mathrm{C}\right)$ & 17.5 & 23.5 & 26.4 & 28.5 & 30.3 & 30.9 & 31.6 & 32.1 & 33.4 & 34.2 & 35.0 \\
Inspected (IC) $\left({ }^{\circ} \mathrm{C}\right)$ & 6.1 & 9.6 & 13.2 & 16.5 & 18.9 & 20.3 & 21.8 & 23.0 & 32.4 & 33.0 & 34.5 \\
\hline
\end{tabular}

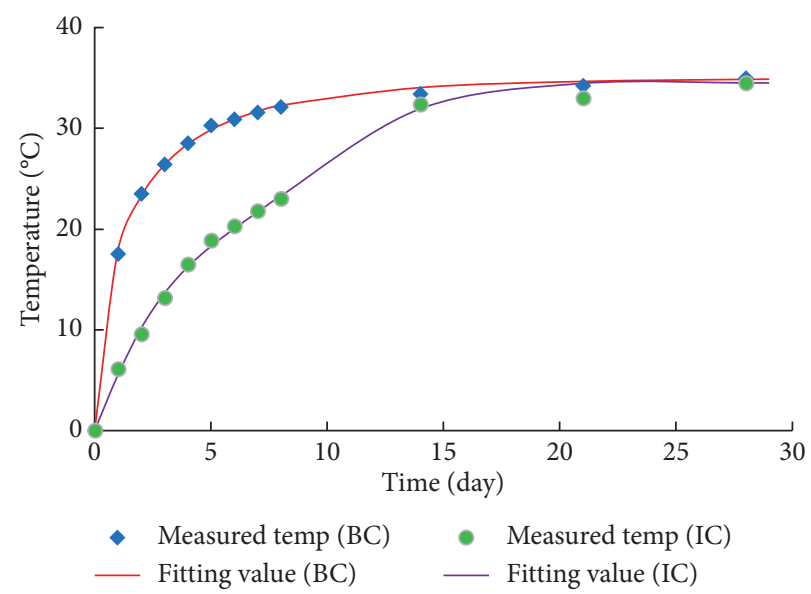

FIGURE 1: Fitting curve of adiabatic temperature rise of $\mathrm{BC}$ and IC.

TABLE 3: Thermodynamic parameters of rock foundation.

\begin{tabular}{lcccc}
\hline $\begin{array}{l}\text { Thermal conductivity } \lambda \\
\left(\mathrm{kJ} /\left(m \cdot d \cdot{ }^{\circ} \mathrm{C}\right)\right)\end{array}$ & $\begin{array}{c}\text { Heat capacity } c \\
\left(\mathrm{~kJ} /\left(\mathrm{kg} \cdot{ }^{\circ} \mathrm{C}\right)\right)\end{array}$ & $\begin{array}{c}\text { Linear expansion } \alpha \\
\left(10^{-6} /{ }^{\circ} \mathrm{C}\right)\end{array}$ & $\begin{array}{c}\text { Elastic modulus } E_{0} \\
(\mathrm{GPa})\end{array}$ & $\begin{array}{c}\text { Poisson's ratio } \mu \\
\begin{array}{l}\text { Density } \rho \\
\left(\mathrm{kg} / \mathrm{m}^{3}\right)\end{array}\end{array}$ \\
\hline 124.92 & 0.858 & 8.0 & 15 & 0.167 \\
\hline
\end{tabular}

TABLE 4: Thermodynamic parameters of concrete.

\begin{tabular}{lccccc}
\hline $\begin{array}{l}\text { Concrete type } \\
\text { C30 }\end{array}$ & $\begin{array}{c}\text { Thermal conductivity } \lambda \\
\left(\mathrm{kJ} /\left(m \cdot d \cdot{ }^{\circ} \mathrm{C}\right)\right)\end{array}$ & $\begin{array}{c}\text { Heat capacity } c \\
\left(\mathrm{~kJ} /\left(\mathrm{kg} \cdot{ }^{\circ} \mathrm{C}\right)\right)\end{array}$ & $\begin{array}{c}\text { Linear expansion } \alpha \\
\left(10^{-6} /{ }^{\circ} \mathrm{C}\right)\end{array}$ & $\begin{array}{c}\text { Finally elastic modulus } E_{0} \\
(\mathrm{GPa})\end{array}$ & $\begin{array}{c}\text { Poisson's ratio } \mu \\
\text { Density } \rho \\
\left(\mathrm{kg} / \mathrm{m}^{3}\right)\end{array}$ \\
\hline Reference $(\mathrm{BC})$ & 185.76 & 0.97 & 10.0 & 32 & 0.167 \\
Inspected (IC) & 185.76 & 0.97 & 10.0 & 32.5 & 2390 \\
\hline
\end{tabular}

(1) Thin wall concrete with a structure thickness of $0.5 \mathrm{~m}$, including the pier wall of aqueduct with two sides free and the tunnel lining with one side free and one side surrounded by rock.

(2) The sluice is built on a rock foundation, and the structural thickness of the sluice floor and pier are both $1.2 \mathrm{~m}$.

(3) For concrete gravity dam, the thickness of pouring layer is $3 \mathrm{~m}$, divided into 6 layers, and the total thickness is $18 \mathrm{~m}$.

4.1. Thin Wall Mass Concrete: Aqueduct Pier Wall and Tunnel Lining. For the pier wall of aqueduct with a structure thickness of $0.5 \mathrm{~m}$, both sides are free; for the tunnel lining also with a structure thickness of $0.5 \mathrm{~m}$, one side is free but the other side is constrained by the surrounding rock. The same thermodynamic parameters are used to calculate by ANSYS. The aqueduct shall be poured in two phases, and the pier wall shall be poured $10 \mathrm{~d}$ after the bottom plate of aqueduct is poured; the tunnel lining shall be poured at one time.

The initial temperature of concrete pouring is $20^{\circ} \mathrm{C}$, and the ambient temperature remains unchanged at $20^{\circ} \mathrm{C}$. Since the aqueduct often uses a suspended construction method and uses a special movable formwork system [26], it does not directly contact the foundation, so the influence of the foundation is not considered. The initial temperature of the surrounding rock of the tunnel is $20^{\circ} \mathrm{C}$. The part of concrete 


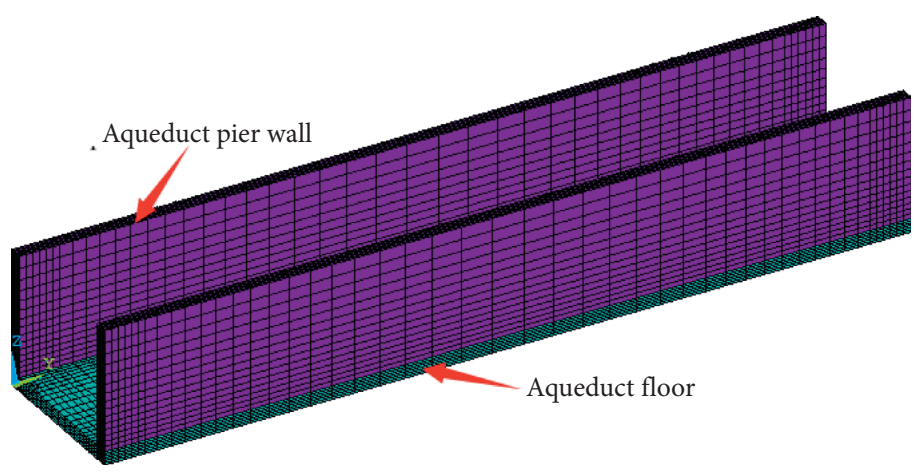

(a)

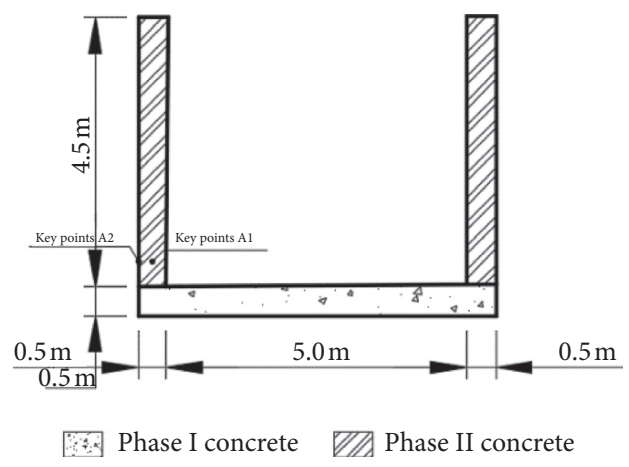

(b)

FIGURE 2: Finite element model and section size of aqueduct.

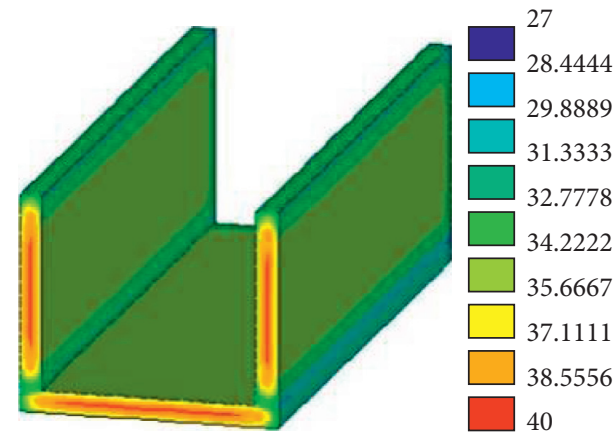

(a)

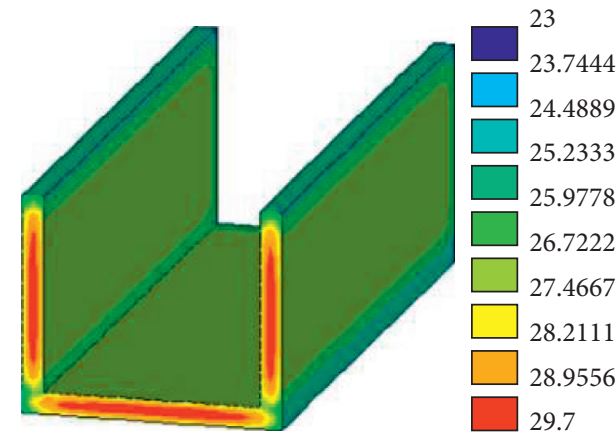

(b)

Figure 3: Temperature envelope diagram of center section of $\mathrm{BC}$ and $\mathrm{IC}\left({ }^{\circ} \mathrm{C}\right)$.

in contact with air shall be treated according to the third boundary condition, meeting the following equation:

$$
\text { boundary condition: }-\lambda\left(\frac{\partial T}{\partial n}\right)=\beta\left(T-T_{a}\right) \text {, }
$$

where $\lambda$ is the thermal conductivity ; $T$ is the temperature; $T_{a}$ is the ambient temperature $; n$ is the normal direction outside the surface; and $\beta$ is the surface heat release coefficient $\left(\beta=\left(400 \mathrm{~kJ} /\left(\mathrm{m}^{2} \cdot \mathrm{d} \cdot{ }^{\circ} \mathrm{C}\right)\right)\right)$.

The length of aqueduct along the water flow direction is $30 \mathrm{~m}$, and the size of aqueduct in the vertical water flow direction is shown in Figure 2.

The pier wall of aqueduct is, respectively, poured with reference concrete and inspected concrete, and the corresponding temperature of each node is calculated by ANSYS, and the maximum temperature of each node is taken out and assigned to the corresponding node to obtain the temperature envelope diagram, as shown in Figure 3.

The results show that the distribution of temperature envelope of reference concrete and inspected concrete is similar, but the temperature range is different. The temperature range of the reference concrete envelope diagram is $27^{\circ} \mathrm{C}-40^{\circ} \mathrm{C}$, while the temperature range of the inspected concrete envelope diagram is $23^{\circ} \mathrm{C}-29.7^{\circ} \mathrm{C}$. The maximum temperature is reduced by $10.3^{\circ} \mathrm{C}$, and the reduction rate is $51.5 \%$.
For massive concrete, the temperature rises and the volume expands at the initial stage of pouring, and the surface concrete is stretched, which is prone to surface cracks. In the later stage of pouring, the temperature drops, the volume shrinks, the internal concrete is under tensile stress, and internal cracks are likely to occur. Therefore, when selecting key points for observation, one is an external point and the other is an internal point. At the joint surface of the new and old concrete, due to the restraining effect of the already poured concrete on the newly poured concrete, the tensile stress near the joint surface area is greater than the area where the highest temperature occurs, as shown in Figures 4-6. At the same time, in the area near the joint surface, due to the influence of old concrete, the temperature is also high as shown in Figure 7. Therefore, points A1 and A 2 in Figure 2 and points P1 and P2 in Figure 8 are selected as key points. However, in actual engineering projects, the center point of the concrete block can be selected as the temperature observation point for temperature control during concrete pouring.

After extracting the temperature change of key points, the arrival time of temperature peak is delayed about $1.4 \mathrm{~d}$.

It can be seen from the stress envelope diagram (Figure 4) that for the thin-walled aqueduct pier wall with no constraint on both sides and only weak constraint on the new and old concrete interface at the bottom, adding 


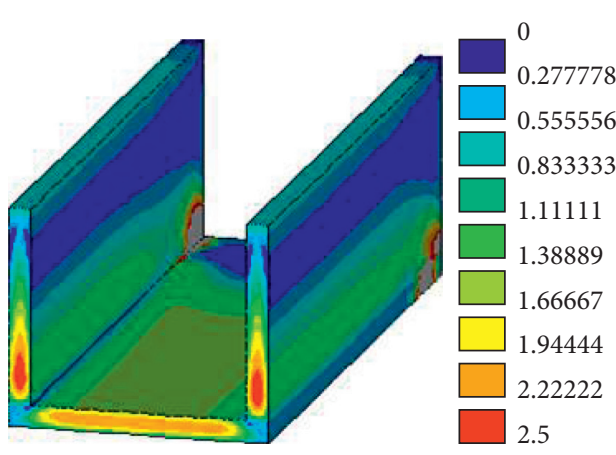

(a)

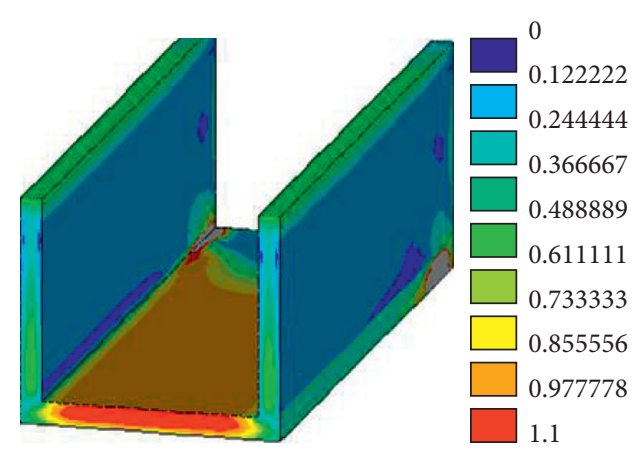

(b)

FIGURE 4: Stress envelope diagram of center section of BC and IC (MPa).

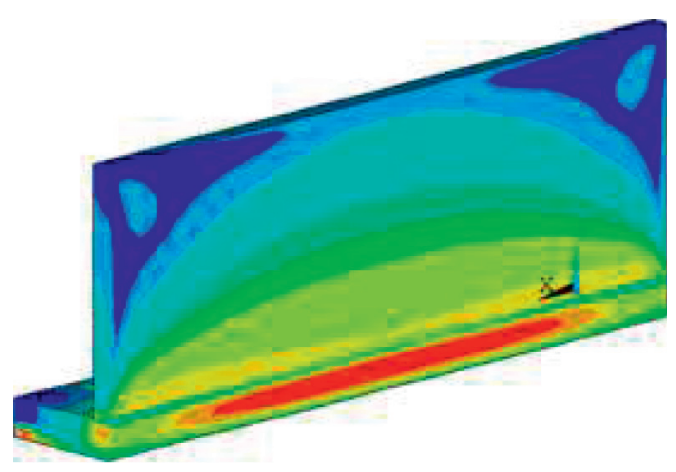

(a)

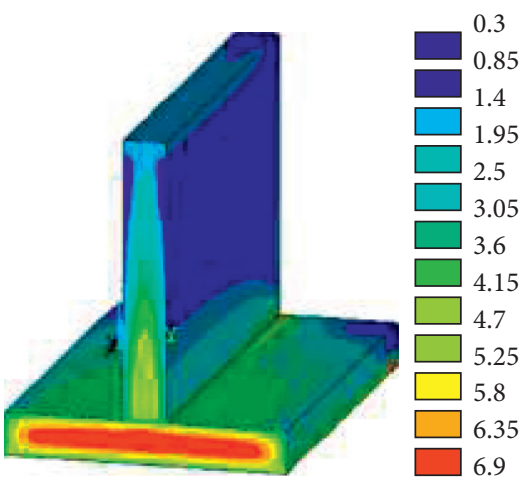

(b)

Figure 5: Stress envelope diagram of sluice model for BC along and vertical to flow direction (MPa).

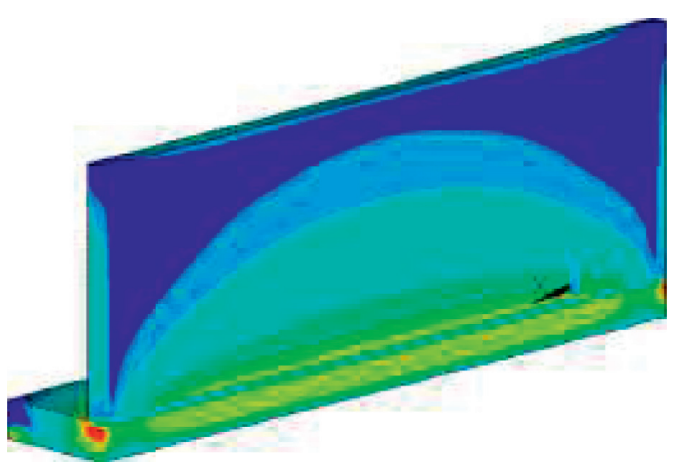

(a)

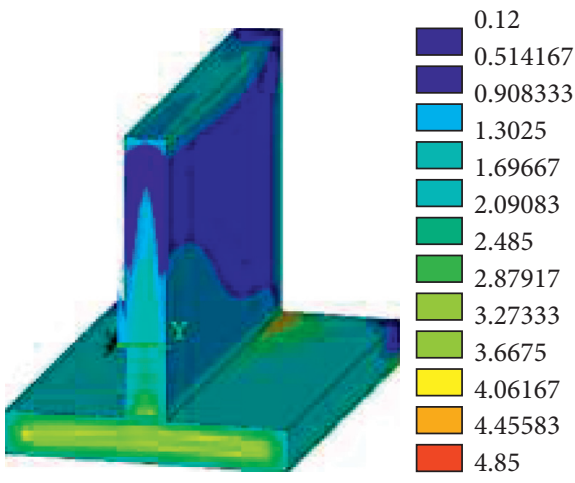

(b)

FIgURE 6: Stress envelope diagram of sluice model for IC along and vertical to flow direction (MPa).

concrete hydration heat inhibitor can reduce the temperature stress of the pier wall from 2.5 $\mathrm{MPa}$ to $0.65 \mathrm{MPa}$, with a reduction rate of $74 \%$, with excellent effect.

A1 is the key point close to the new old interface inside the pier wall, so the internal area is first subjected to compressive stress during the temperature rise stage; when the temperature decreases, there is a tension trend gradually, and the final performance is tension. It can be seen from Figure 9 that the maximum tensile stress does not exceed the tensile strength, but the maximum tensile stress of the inspected concrete is obviously smaller than the tensile strength, and the structural thermal stress is smaller, which is much safer.

A2 is the key point close to the new old interface outside the pier wall. In the stage of temperature rise, due to the expansion of concrete, it shows tensile stress. In the stage of temperature decreasing, the tensile stress decreases gradually. In the later stage, the direction of the main stress changed, and it still shows tensile stress. It can be seen from 


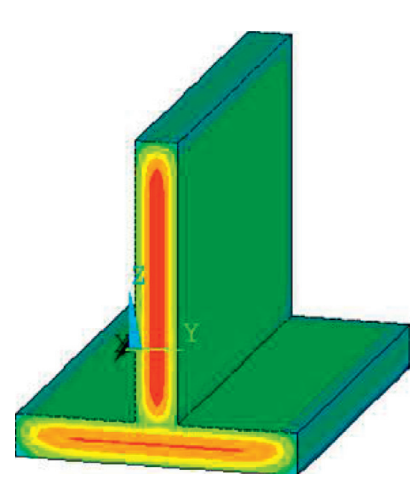

(a)

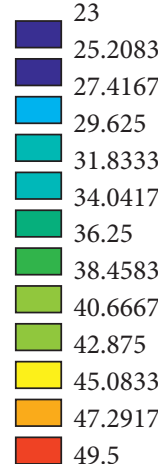

49.5

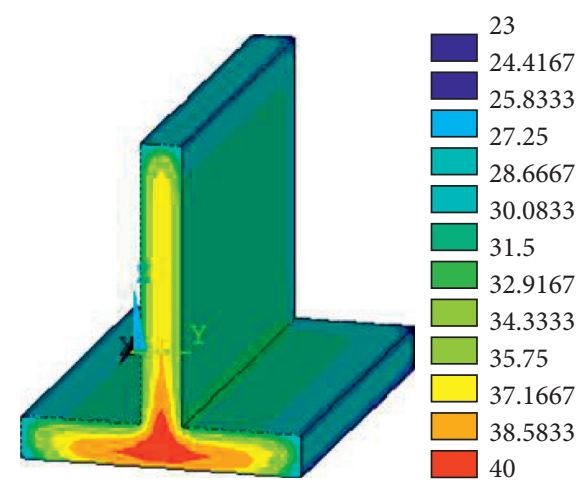

(b)

Figure 7: Temperature envelope diagram of $\mathrm{BC}$ and IC in vertical flow direction of sluice model $\left({ }^{\circ} \mathrm{C}\right)$.

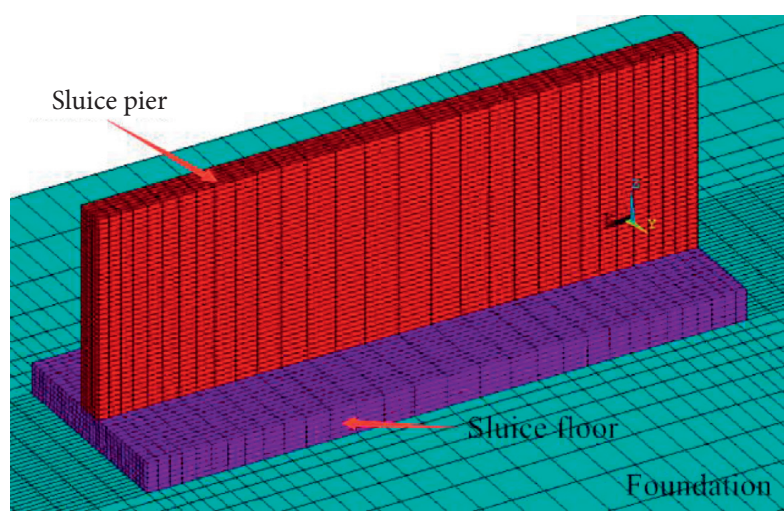

(a)

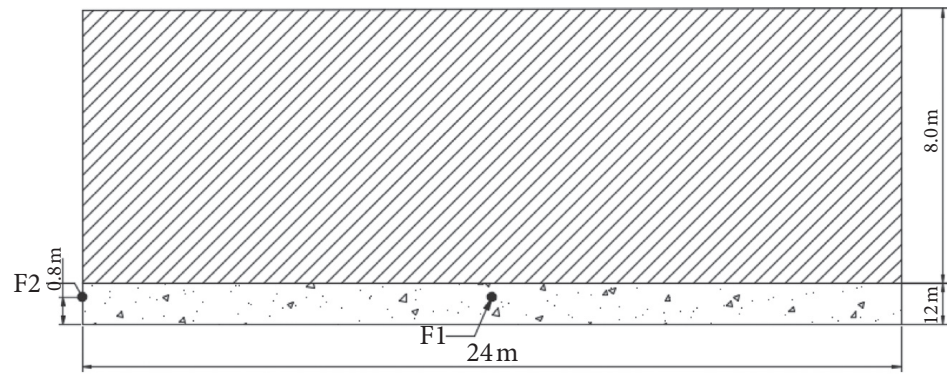

Phase I concrete

[7 Phase II concrete

(b)

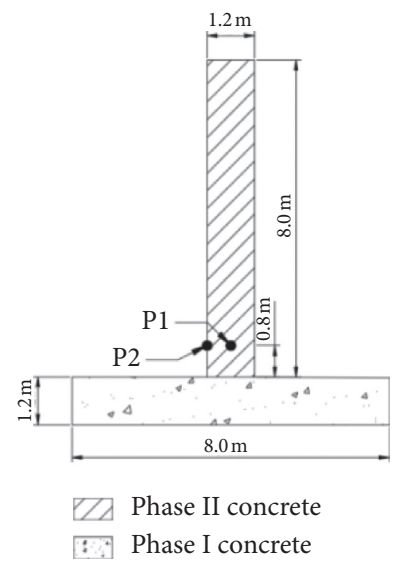

(c)

Figure 8: The finite element model, structure size, and key points of the sluice.

Figure 9 that the surface point is dangerous at the initial stage of pouring, and the tensile stress under this condition does not exceed the tensile strength. However, due to the delay of the peak temperature of the inspected concrete, the initial surface tensile stress rise is relatively gentle, which is much safer.

In the actual projects, the concrete strength of aqueduct is higher, so the final value of adiabatic temperature rise is higher, which can reach $80^{\circ} \mathrm{C}$. Therefore, the reference concrete with low safety reserve is easy to cause temperature cracks, and the addition of hydration heat inhibitor can reduce the maximum tensile stress and increase the safety reserve, which is beneficial to prevent temperature cracks.

In order to study the influence of structural constraints on the action of hydration heat inhibitors, a tunnel lining model is established. The tunnel lining is strongly constrained by the surrounding rock. The diameter of the tunnel is $3 \mathrm{~m}$, of which the thickness of the concrete lining is $0.5 \mathrm{~m}$ 


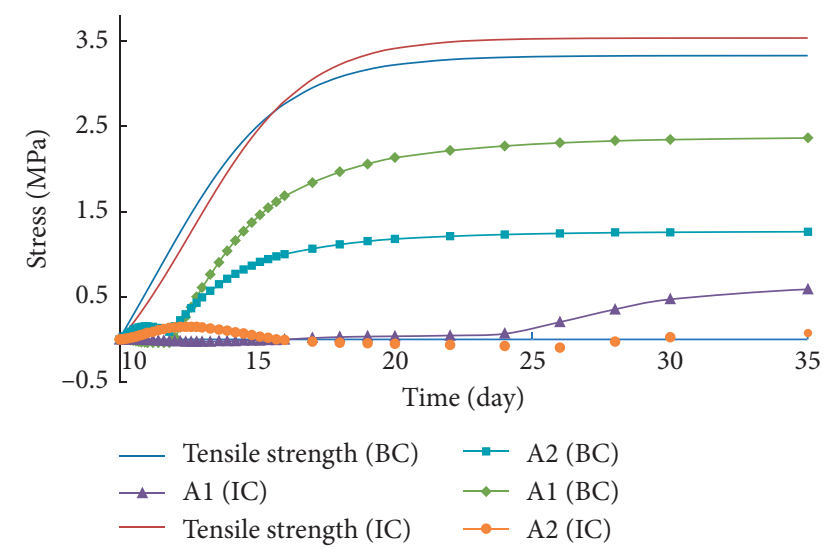

FIGURE 9: Change curve of principal stress with age at key points of aqueduct.

and the length along the flow direction is $20 \mathrm{~m}$. The reference concrete and the inspected concrete are used for pouring, respectively.

By solving the temperature field and drawing the temperature envelope diagram, the distribution rule of the temperature envelope diagram of the reference concrete and the inspected concrete is similar, but the temperature range changes greatly. The temperature range of the reference concrete envelope diagram is $27^{\circ} \mathrm{C}-38^{\circ} \mathrm{C}$, while the temperature range of the inspected concrete envelope diagram is $24^{\circ} \mathrm{C}-29.6^{\circ} \mathrm{C}$. The maximum temperature drops by $8.4^{\circ} \mathrm{C}$, and the reduction rate is $46.7 \%$. The arrival time of the temperature peak is delayed, and the delay time of the central temperature peak of the tunnel lining is about $2.1 \mathrm{~d}$. At the same time, the reference concrete temperature rises rapidly and falls rapidly, while the temperature of the inspected concrete changes gently.

The tunnel lining concrete is constrained by the surrounding rock. Therefore, in the stage of temperature rise, the whole section is compressed, and the concrete has no risk of cracking. In the stage of temperature decrease, there is a tension trend in the whole section, and the tensile stress increases gradually.

From the stress envelope diagrams (Figures 10 and 11), it can be seen that the thermal stress of the tunnel lining is greater than that of the aqueduct pier wall. The maximum tensile stress of the reference concrete is up to $5.2 \mathrm{MPa}$, exceeding the tensile strength of $3.3 \mathrm{MPa}$, and the concrete will have a great risk of cracking. However, the maximum tensile stress of the inspected concrete is only 2.4 MPa, which is less than the tensile strength of $3.5 \mathrm{MPa}$. The maximum tensile stress reduction rate is $54 \%$, and the effect of using inhibitor is significant.

In summary, for the thin-walled mass concrete, adding the inhibitor will greatly reduce the temperature peak of the structure and delay the arrival time of the temperature peak so as to greatly reduce the thermal stress of the structure and prevent temperature cracks. Moreover, the less the structure is constrained, the stronger the effect of the inhibitor on reducing the thermal stress of the structure is.
4.2. Mass Concrete of Medium Thickness: Sluice on Rock Foundation. In order to study the temperature control effect of hydration heat inhibitor when the thickness of mass concrete structure increases, the finite element model of sluice is established. As shown in Figure 8, the thickness of sluice floor and pier is $1.2 \mathrm{~m}$, which is built on rock foundation, and the length along the flow direction is $24 \mathrm{~m}$. The calculation parameters are the same as those of aqueduct and tunnel lining. The initial temperature of the foundation is $20^{\circ} \mathrm{C}$.

It can be seen from the temperature envelope diagram (Figure 7) that the mode of temperature peak distribution changes greatly. The reason is that when the thickness of concrete structure increases, the inhibitor keeps the temperature of sluice stable after reaching the peak, as shown in Figure 12.

After that, the hydration heat produced by pouring of the pier is transmitted to the joint surface of the sluice floor and pier, and the two parts of heat are accumulated, which makes the temperature rise again, even higher than the first temperature peak, so the temperature envelope diagram changes.

The effect of the inhibitors on the temperature reduction of medium wall thickness structure is still significant. The maximum temperature of sluice floor decreases from $47.4^{\circ} \mathrm{C}$ to $39.6^{\circ} \mathrm{C}$, and the reduction rate is $28.2 \%$, and the time of temperature peak arrival is delayed about $3.2 \mathrm{~d}$. The maximum temperature of sluice pier decreases from $48.6^{\circ} \mathrm{C}$ to $37.4^{\circ} \mathrm{C}$, and the reduction rate is $39.2 \%$, and the time of temperature peak arrival is delayed about $2.1 \mathrm{~d}$. However, due to the temperature rise of new and old concrete interface caused by the inhibitor, the total maximum temperature of the sluice decreases from $48.6^{\circ} \mathrm{C}$ to $39.6^{\circ} \mathrm{C}$, and the reduction rate is $31.4 \%$.

From the stress envelope diagrams (Figures 5 and 6), it can be seen that the thermal stress of the sluice is obviously reduced after adding the inhibitor.

It can be obtained from Figure 13 that the tensile stress in the internal area of sluice floor is $6.8 \mathrm{MPa}$, which exceeds the tensile strength and reduces to $3.4 \mathrm{MPa}$, which is lower than the tensile strength, with a reduction rate of $50 \%$. The external area of sluice floor is affected by the new pouring layer, and the stress has a secondary peak. The maximum tensile stress reaches $6.0 \mathrm{MPa}$, which is $2.7 \mathrm{MPa}$ higher than the tensile strength. After adding the inhibitor, the tensile stress decreases to $4.7 \mathrm{MPa}, 1.2 \mathrm{MPa}$ higher than the tensile strength, and the reduction rate is $21.7 \%$.

It can be obtained from Figure 14 that the tensile stress in the internal area of the pier is reduced from 5.2 $\mathrm{MPa}$ to $2.5 \mathrm{MPa}$, and the reduction rate is $51.9 \%$, so the effect is obvious. For the external area of the pier, the concrete is compressed in the early age. When the reference concrete is used for pouring, the tensile stress increases rapidly in the early age, which will exceed the tensile strength of concrete at the corresponding age, so surface cracks will occur. When the inspected concrete is used for pouring, the tensile stress growth is less than the corresponding tensile strength, and there will be no surface cracks. 


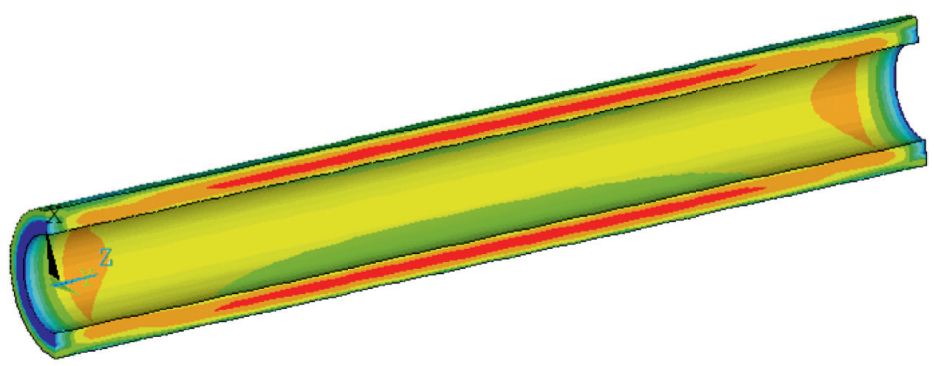

(a)
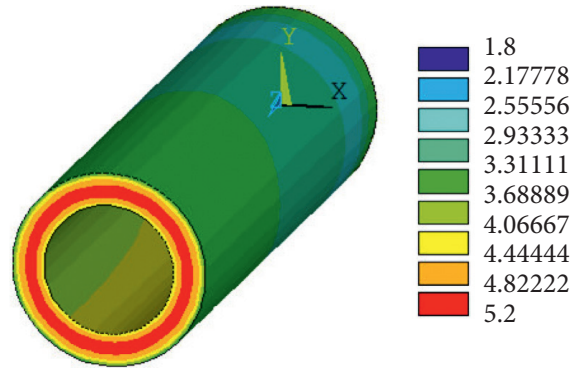

(b)

Figure 10: Stress envelope diagram of tunnel model for BC along and vertical to flow direction (MPa).

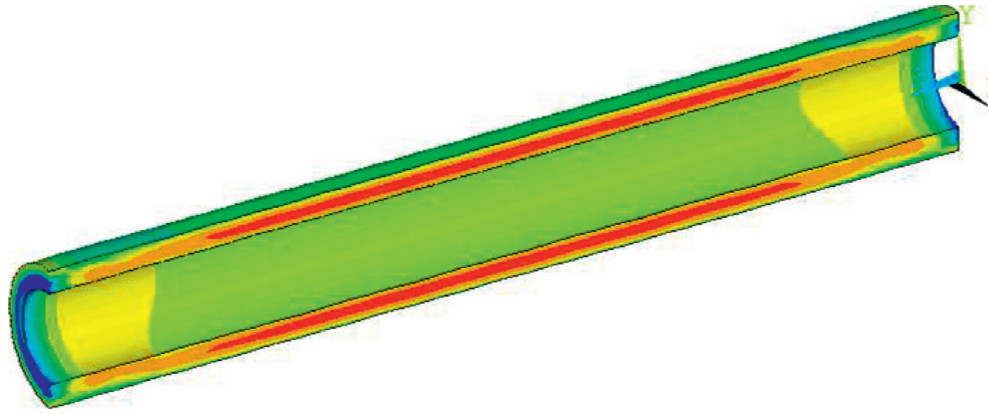

(a)

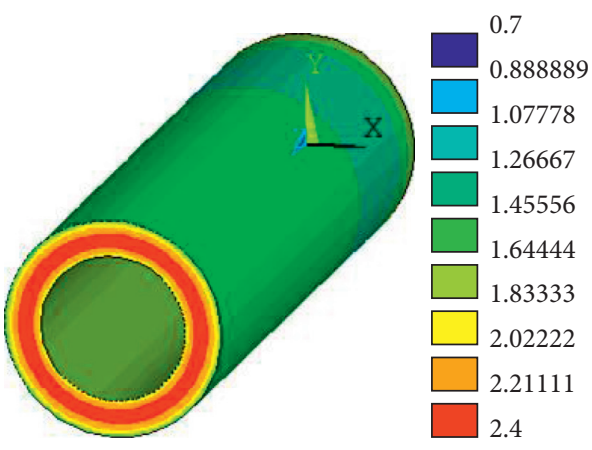

(b)

FIgURE 11: Stress envelope diagram of tunnel model for IC along and vertical to flow direction (MPa).

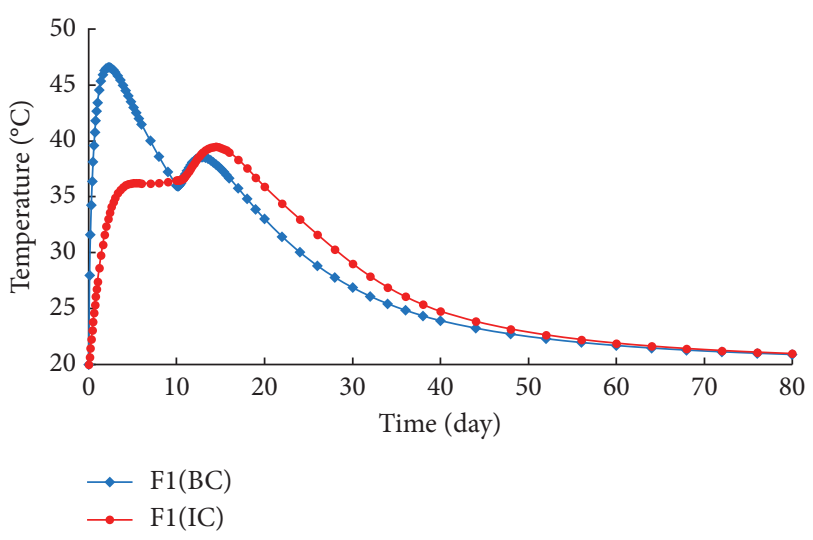

FIgURE 12: Temperature duration curve of key points F1 and F2 of sluice floor.

4.3. Mass and Thick Concrete: Concrete Gravity Dam. Because the gravity dam has large volume and thick concrete, it is more necessary to consider the thermal stress. Compared with the previous model, the concrete structure is thicker and the concrete grade is lower. C20 concrete is selected here. Dam concrete generally uses low-heat cement, so the concrete hydration reaction emits less heat, and the final value of the adiabatic temperature rise decreases. Change the calculation parameters here as shown in Table 5, making the simulation more in line with the engineering practice.

As shown in Figure 15, some pouring layers of the concrete gravity dam are selected for simulation. As shown in Figure 16, the length along the flow direction is $60 \mathrm{~m}$, and the length in the vertical flow direction is $20 \mathrm{~m}$; the upstream side of the dam is vertical, and the downstream slope is 1 : 0.75 ; the structure thickness is $18 \mathrm{~m}$, which is poured in six layers, each layer is $3 \mathrm{~m}$, and the interval period of pouring is $10 \mathrm{~d}$. The rock foundation calculation parameters are the same as before. The initial temperature of the dam foundation is $20^{\circ} \mathrm{C}$.

It can be seen from the temperature envelope (Figure 17) that the dam temperature is high inside and low outside, and the temperature of the new and old concrete interface is also higher because of the heat which is difficult to dissipate. After adding the inhibitor, the maximum temperature of the dam increases from $44.5^{\circ} \mathrm{C}$ to $46.4^{\circ} \mathrm{C}$, and the increasing rate is $7.7 \%$, which leads to the increase of temperature difference between internal and external area of the concrete.

The reason for the increase of temperature peak is that the inhibitor slows down the heat release rate of concrete at early stage, so the heat emitted through the surface is less during the interval of pouring, and the heat accumulation leads to the increase of temperature; at the same time, the occurrence time of temperature peak is delayed, and the arrival time of temperature peak in the internal area with higher temperature is generally delayed about $10 \mathrm{~d}$.

From the stress envelope diagrams (Figures 18 and 19), it can be seen that the total maximum stress decreases from 6.3 $\mathrm{MPa}$ to $5.4 \mathrm{MPa}$, and the reduction rate is $14.3 \%$, after adding the inhibitor. The stress distribution changes greatly, and the maximum tensile stress inside the dam is 


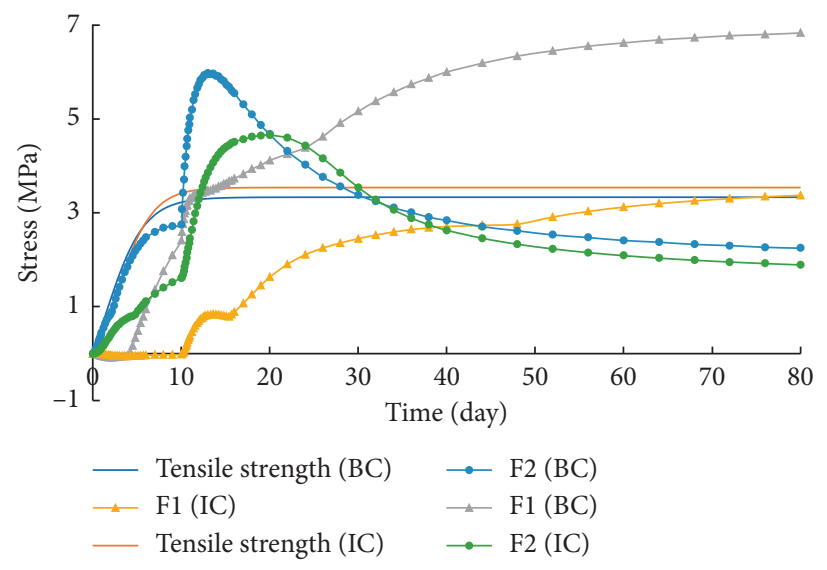

FIgURE 13: Stress duration curve of key points F1 and F2 of sluice floor.

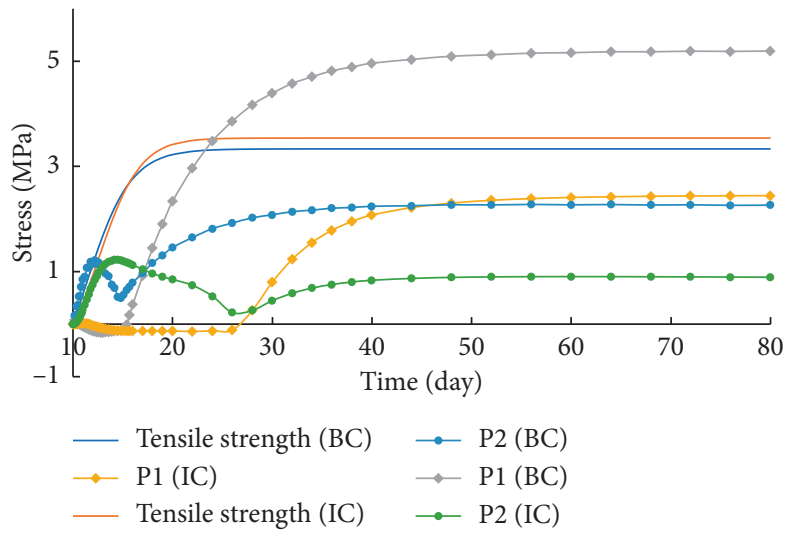

Figure 14: Stress duration curve of key points P1 and P2 of sluice floor.

TABLe 5: Adiabatic temperature rise and elastic modulus expression of concrete gravity dam.

\begin{tabular}{|c|c|}
\hline Concrete type C20 & Expression \\
\hline \multicolumn{2}{|l|}{ Reference $(B C)$} \\
\hline$\theta$ & $\theta(\tau)=28.0 *\left[1-e^{-0.7141 \tau^{0.6129}}\right]\left({ }^{\circ} \mathrm{C}\right)$ \\
\hline E & $E(\tau)=25.35 *\left(1-e^{-0.4259 * \tau^{0.9633}}\right)(\mathrm{GPa})$ \\
\hline \multicolumn{2}{|l|}{ Inspected (IC) } \\
\hline$\theta$ & $\theta(\tau)=16.8 *\left[1-e^{-0.3214 \tau^{1.1254}}\right]+11.2 *\left[1-e^{-0.0006 \tau^{3.0227}}\right]\left({ }^{\circ} \mathrm{C}\right)$ \\
\hline$E$ & $E(\tau)=26.0 *\left(1-e^{-0.3068 * \tau^{1.0994}}\right)(\mathrm{GPa})$ \\
\hline
\end{tabular}

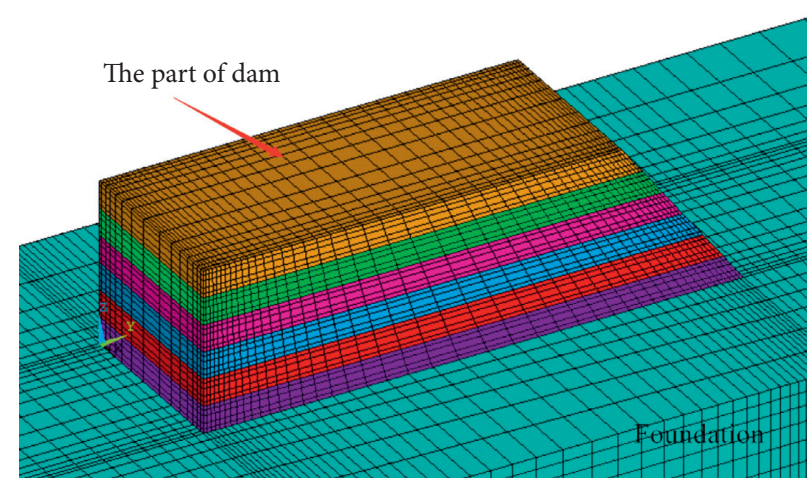

Figure 15: Finite element model of concrete dam. 


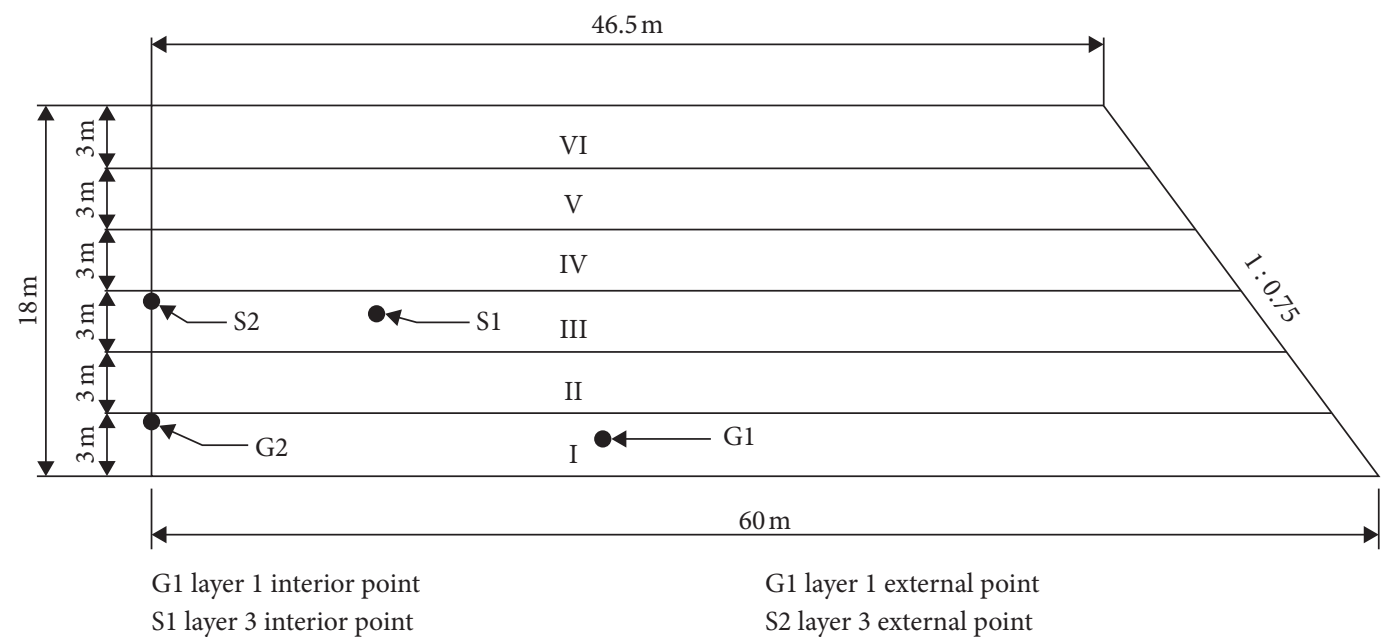

Figure 16: Part of a gravity dam size and key point diagram.

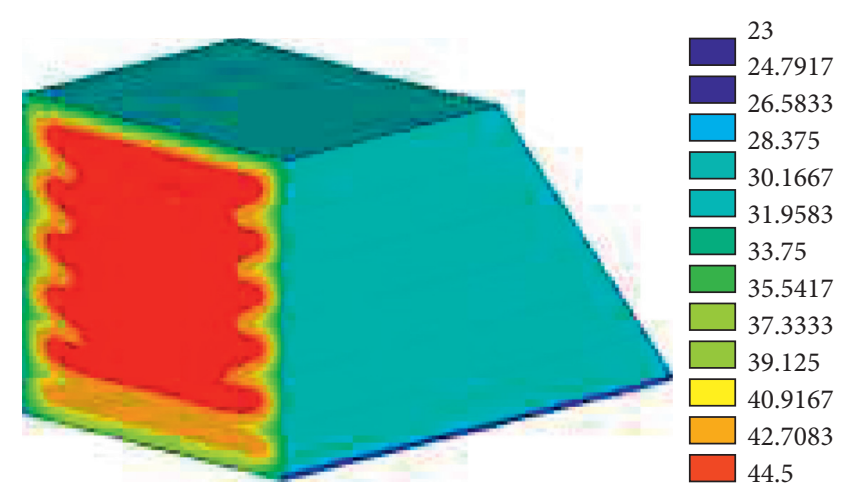

(a)

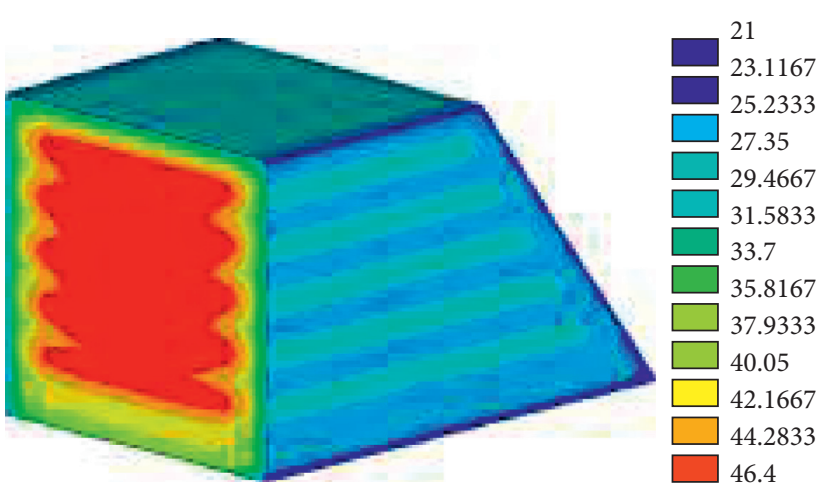

(b)

Figure 17: Temperature envelope diagram of BC and IC in vertical flow direction of dam model $\left({ }^{\circ} \mathrm{C}\right)$.

significantly reduced, but the maximum tensile stress on the outer surface of the new old concrete interface increases.

The area with large tensile stress is the internal area of the first layer. Taking the duration data of key point G1, the maximum tensile stress is reduced from $6.27 \mathrm{MPa}$ to $4.43 \mathrm{MPa}$, with a reduction rate of $29.3 \%$. The reason for the decrease of internal area stress is that the inhibitor delays the arrival of temperature peak, and the elastic modulus has enough time to rise. In the early stage of temperature rise, the concrete expands outwards and the internal area is compressed; when the temperature reaches the peak, the compressive stress stored in the inspected concrete is much more than that in the reference concrete. As shown in Figure 20, the maximum compressive stress of reference concrete along the flow direction is less than that of the inspected concrete. Therefore, in the stage of temperature decrease, the concrete tends to shrink, these stored compressive stresses are gradually offset, and tensile stresses gradually increase. During the period from the beginning of temperature drop to the temperature stabilization, because the temperature drop is approximately the same, the elastic modulus is similar, so the total shrinkage is similar, and the accumulated tensile stress in each step is similar. However, the ultimate tensile stress of the inspected concrete is less because more compressive stress is stored in the temperature rise stage.

External area with high tensile stress is the external surface of the new old concrete interface. According to the stress envelope diagram and stress duration curve, it can be seen that the maximum tensile stress increases from 4.97 $\mathrm{MPa}$ to $5.31 \mathrm{MPa}$ after the addition of the inhibitor, with increasing rate of $6.8 \%$, which is similar to the $7.7 \%$ increase in temperature. This is due to the increase of internal and external temperature difference, which makes the horizontal expansion effect of concrete more obvious, resulting in the increase of surface tensile stress.

Therefore, when the thickness of the structure increases, using the inhibitor to reduce the thermal stress has limitations. The hydration heat inhibitor will cause a slight increase in the maximum temperature of the structure, which can reduce the internal tensile stress, but the surface tensile stress will increase slightly.

When only plain concrete is used for pouring, the thermal stress of mass concrete with large thickness often exceeds the tensile strength, resulting in cracks; Only adding 


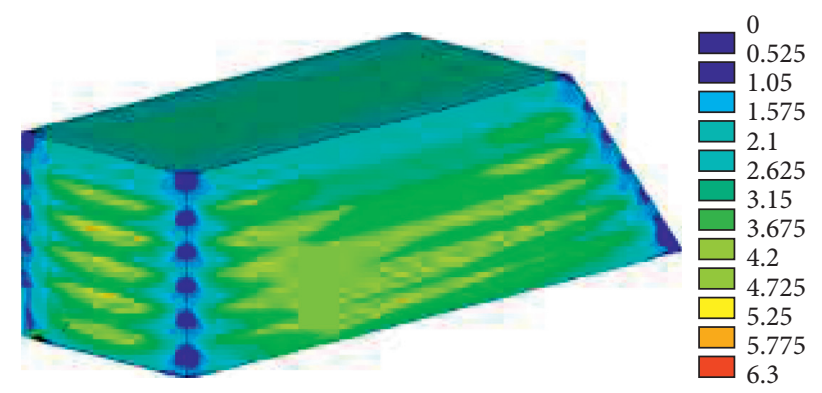

(a)

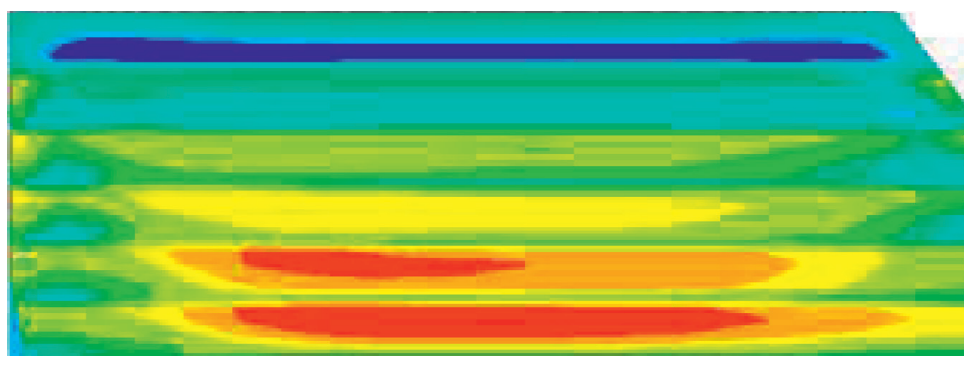

(b)

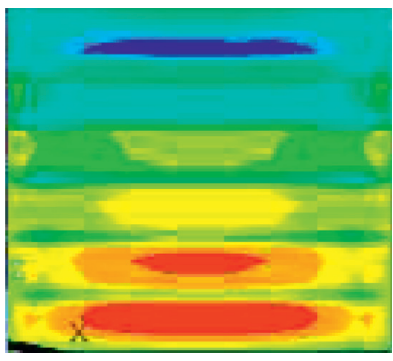

(c)

FIGURE 18: Stress envelope diagram of external surface, cross section, and longitudinal section of BC dam (MPa).

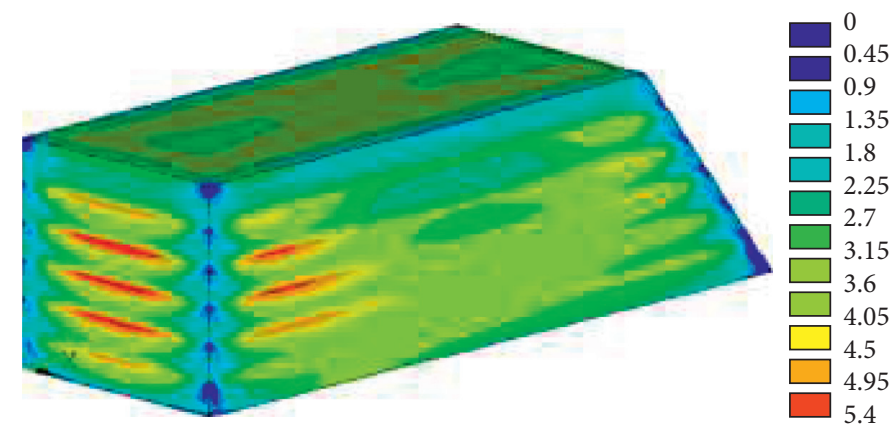

(a)

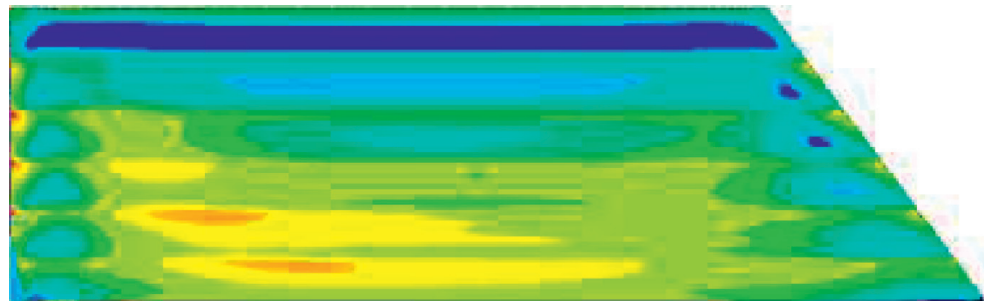

(b)

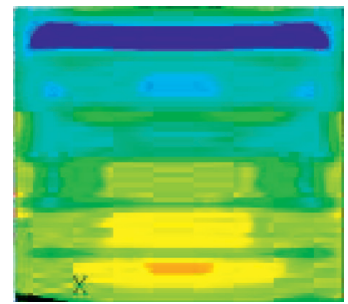

(c)

FIgURE 19: Stress envelope diagram of external surface, cross section, and longitudinal section of IC dam (MPa).

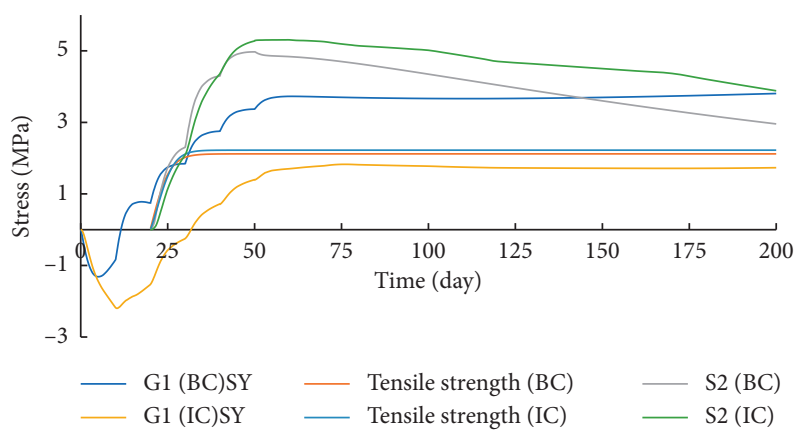

Figure 20: Stress duration curve along the flow direction of G1 and principal stress duration curve of S2 (200 d). 
TABLE 6: Experimental concrete mix ratio $\left(\mathrm{kg} / \mathrm{m}^{3}\right)$.

\begin{tabular}{lcccccc}
\hline Concrete type & Water & Cement & Fly ash & Sand & Aggregate & HHC-S \\
\hline BC & 159 & 325 & 71 & 748 & 1040 & 1040 \\
IC & 159 & 325 & 71 & 748 & 8 \\
\hline
\end{tabular}

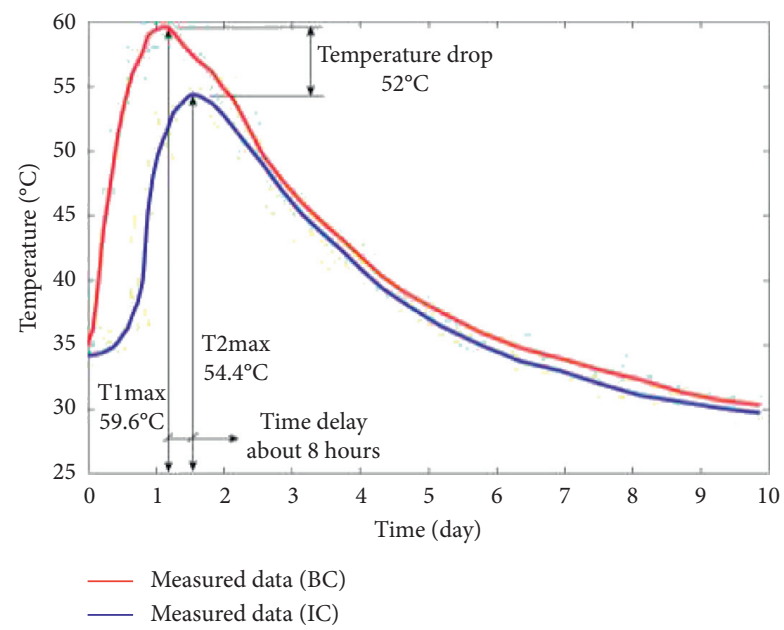

FIgURE 21: Temperature duration curve of reference concrete and inspected concrete at center point of side wall.

TABLe 7: Thermal parameters of the side wall.

\begin{tabular}{lccc}
\hline & $\begin{array}{c}\text { Thermal conductivity } \lambda \\
\left(\mathrm{kJ} /\left(\mathrm{m} \cdot \mathrm{d} \cdot{ }^{\circ} \mathrm{C}\right)\right)\end{array}$ & $\begin{array}{c}\text { Heat capacity } c \\
\left(\mathrm{~kJ} /\left(\mathrm{kg} \cdot{ }^{\circ} \mathrm{C}\right)\right)\end{array}$ & $\begin{array}{c}\text { Density } \rho \\
\left(\mathrm{kg} / \mathrm{m}^{3}\right)\end{array}$ \\
\hline Concrete & 257.28 & 0.995 & 2351 \\
Foundation & 116.64 & 1.600 & 1900 \\
\hline
\end{tabular}

the hydration heat inhibitor, the surface cracks will still occur, and the internal tensile stress, although reduced, still exceeds the tensile strength. The calculation does not consider concrete creep, and the tensile stress will be larger. However, if the concrete is not cracked and the tensile stress is less than the tensile strength, other temperature control measures such as arranging cooling water pipe, strengthening surface insulation, and so on are still needed.

\section{Experiment Validation}

5.1. Experimental Results. In order to verify the reliability of numerical simulation and study the effect of hydration heat inhibitors in actual projects, field experiments were carried out. The concrete block poured in the experiment is a subway side wall under construction in Shenzhen, China, with a thickness of $0.7 \mathrm{~m}$, a height of $5 \mathrm{~m}$, and a length of $25 \mathrm{~m}$. The mixing ratio of concrete is listed in Table 6 . The amount of hydration heat inhibitor added is $2 \%$ of the mass of the gel material (cement and fly ash).

The temperature duration curve of reference concrete (BC) and inspected concrete (IC) at center point of the side wall is measured, as shown in Figure 21.

It can be seen from Figure 21 that after adding the hydration heat inhibitor, the maximum temperature of the center point of the concrete structure is reduced by $5.2^{\circ} \mathrm{C}$, the reduction is about $21.2 \%$, and the time of the peak temperature is delayed by about $8 \mathrm{~h}$. Therefore, for thin-walled mass concrete, the addition of hydration heat inhibitors can effectively reduce the peak temperature of the concrete and delay the time of the peak temperature, and the temperature control effect is obvious. The thermal stress of mass concrete will also be reduced, thereby preventing temperature cracks.

5.2. Numerical Simulation Results. The finite element model of the side wall was established, and the temperature field of the side wall was calculated and compared with the measured value. The thermal parameters required for calculation are obtained through experiments, as shown in Table 7 . The initial temperature of the foundation is $31^{\circ} \mathrm{C}$, the pouring temperature of reference concrete (BC) is $35.1^{\circ} \mathrm{C}$, and the pouring temperature of the inspection concrete (IC) is $34.2^{\circ} \mathrm{C}$. The steel formwork is used for pouring, so the heat dissipation coefficient of the concrete surface is high, $\beta=\left(1920 \mathrm{~kJ} /\left(\mathrm{m}^{2} \cdot \mathrm{d} \cdot{ }^{\circ} \mathrm{C}\right)\right)$. The pouring time is May 16,2020 , so the ambient temperature is selected as the local temperature during that period.

The adiabatic temperature rise formulas used in the calculation are equations (14) and (15). The calculation results are shown in Figures 22 and 23. 


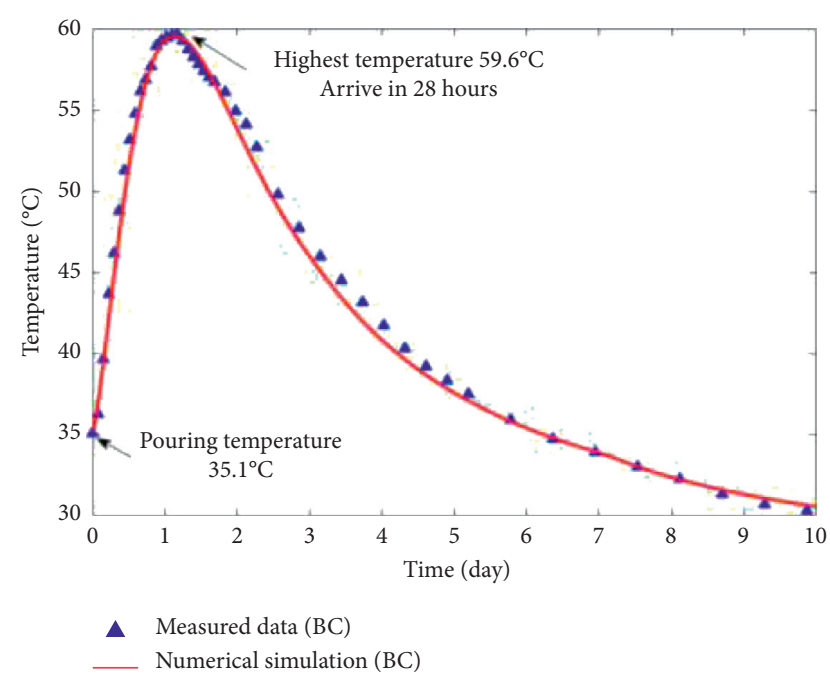

FIGURE 22: Comparison of measured and simulated temperature duration curves of reference concrete (BC).

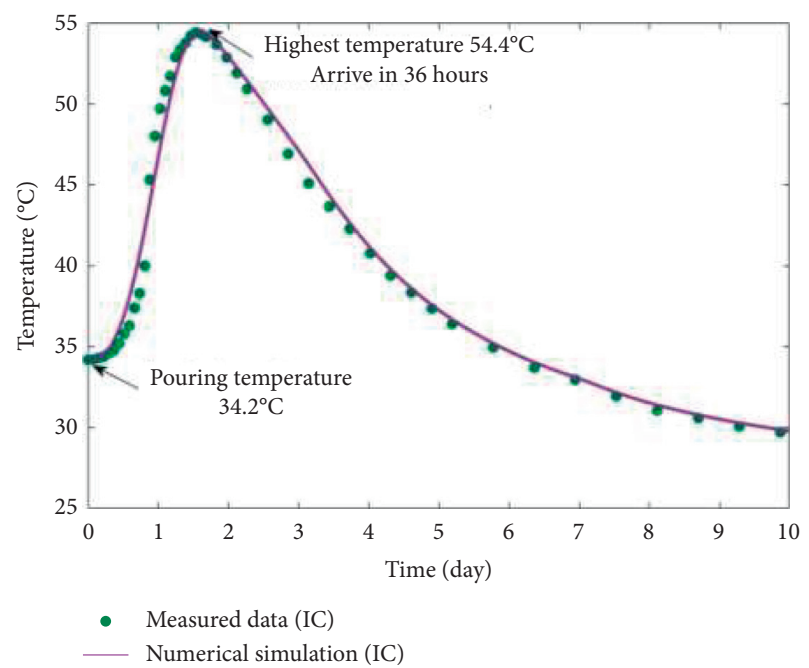

FIGURE 23: Comparison of measured and simulated temperature duration curves of inspected concrete (IC).

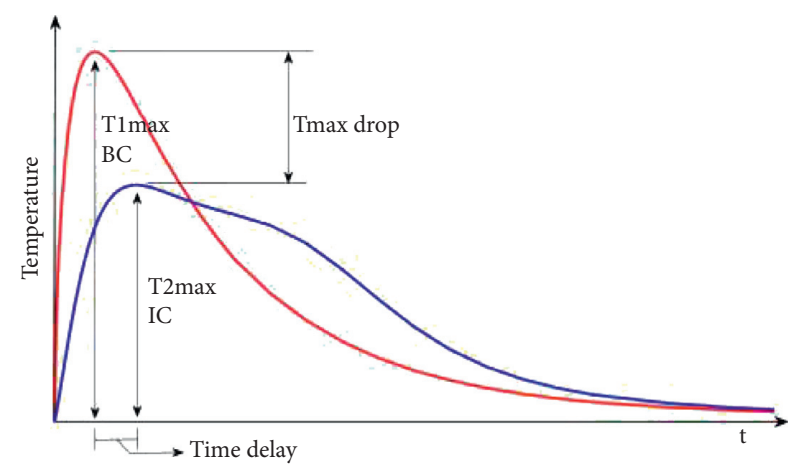

FIgURE 24: Typical temperature duration curve of the center point of concrete block.

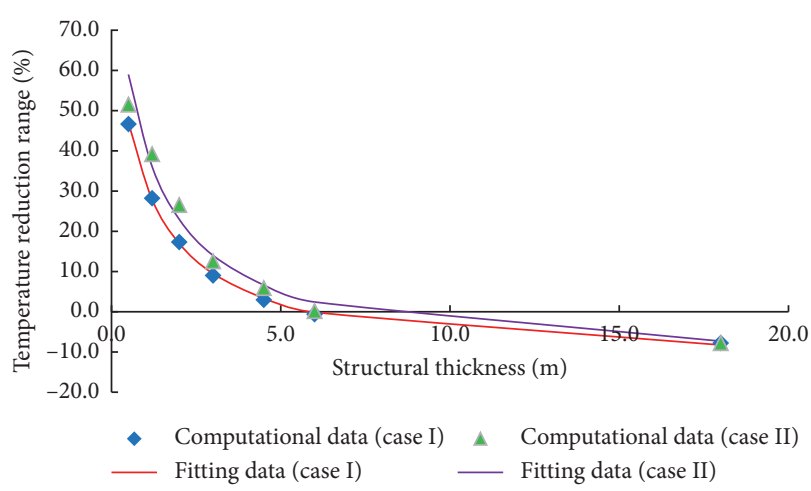

FIgURE 25: Comparison between ANSYS calculation data and fitting formula.

$$
\begin{gathered}
B C: \theta(\tau)=54.8 *\left[1-e^{-1.3 \tau^{1.4}}\right] \\
I C: \theta(\tau)=18 *\left[1-e^{-0.6 \tau^{3.5}}\right]+33 *\left[1-e^{-0.4 \tau^{1.8}}\right] .
\end{gathered}
$$

It can be seen from Figures 22 and 23 that the results obtained by numerical simulation are in good agreement with the measured temperature data. The numerical simulation can also reflect the feature that after the hydration heat inhibitor is added, the temperature peak decreases and the temperature peak delays temporarily. Therefore, it is reasonable and reliable to use the obtained thermodynamic parameters and numerical simulation to study the temperature field and stress field of mass concrete.

\section{Conclusion}

6.1. Rule of Temperature. It can be seen from Figure 24 that because HHC-S reduces the early hydration heat release rate of concrete, the time of the peak temperature is delayed, and the concrete has a longer time to radiate heat through the boundary during the hydration heat release period, so the temperature peak decreases. The measured data and numerical simulations have verified this conclusion well.

The effect of the hydration heat inhibitors on reducing the temperature peak is inversely proportional to the thickness of the structure. At the same time, the effect of inhibitors on reducing the temperature peak is also related to the structure constraints.

This is well explained by equation (16). In the stage of increasing concrete temperature, when the concrete structure is thinner, $\left(Q_{\text {rise }} / Q_{\text {total }}\right)$ is smaller and $\left(Q_{\text {lost }} / Q_{\text {total }}\right)$ is larger, so the $T_{\max }$ decreases more; at the same time, boundary conditions affect the value of $\left(Q_{\text {lost }} / Q_{\text {total }}\right)$, so different boundary conditions have different effects.

$$
\left(\frac{Q_{\text {rise }}}{Q_{\text {total }}}\right)+\left(\frac{Q_{\text {lost }}}{Q_{\text {total }}}\right)=1,
$$

where $Q_{\text {total }}$ represents the total heat released from the hydration reaction; BC and IC are the same; $Q_{\text {rise }}$ represents the heat that raises the temperature of the concrete, which is 
directly related to $T_{\max }$; and $Q_{\text {lost }}$ represents the heat dissipated by the concrete through the boundary.

Analyze the temperature data in the case and change the thickness of the sluice floor and the pier to $2 \mathrm{~m}, 3 \mathrm{~m}, 4.5 \mathrm{~m}$, and $6 \mathrm{~m}$. The result is shown in Figure 25 .

The relationship between the thickness of concrete structure $H(m)$ and the maximum temperature reduction rate $Q(\%)$ is put forward as follows:

$$
Q=\varphi\left(\frac{90}{(H+1)}\right)-13,
$$

where $Q$ is the reduction rate of the temperature, $\% ; \varphi$ is heat sink coefficient of the structure (when there are two large free surfaces (case I), $\varphi=1.0$; when there is one large free surface (case II), $\varphi=1.2$ ); and $H$ is the total thickness of the structure, $m$.

According to equation (17), when the thickness of concrete structure reaches about $6 \mathrm{~m}$, the inhibitor cannot reduce the maximum temperature of the structure. When the thickness of the structure exceeds $6 \mathrm{~m}$, the maximum temperature and the temperature difference between internal and external area of the structure will increase with the thickness, which will lead to the occurrence of surface cracks.

The arrival time of temperature peak is generally delayed with the increase of structure thickness. At the same time, it is also related to the structural constraints. The stronger the structural constraints, the later the arrival time of temperature peak. After the temperature peak is delayed, the elastic modulus has enough time to increase during the temperature rise, so as to increase the internal compressive stress of the structure during the temperature rise, so that the internal tensile stress will be reduced during temperature drop, which is beneficial to reduce temperature cracks in the structure.

In addition, different addition amounts of hydration heat inhibitors will have different effects, and the temperature peak reduction range and temperature peak delay time will be different. Detailed research in this direction will be carried out in the next stage.

6.2. Rule of Stress. For thin-walled structures such as aqueduct pier wall and tunnel lining, adding hydration heat inhibitor can reduce the temperature peak about $50 \%$, delay the arrival time of the temperature peak about $1.5 \mathrm{~d}$, and effectively reduce the thermal stress within the tensile strength. For the structure with weak constraint, the thermal stress can be reduced more than $70 \%$, and for the structure with strong constraint, the thermal stress can be reduced about $45 \%$.

For the hydraulic structures with medium wall thickness, such as the sluice on the rock foundation, the addition of the inhibitor reduces the temperature peak by about $30 \%$ and delays the arrival of temperature peaks for about $2 \mathrm{~d}$, effectively reducing the structural thermal stress. The internal thermal stress is reduced by $50 \%$ to meet the tensile strength, and the surface thermal stress is also reduced by more than $20 \%$. Therefore, in the case of using the inhibitor, for the parts with strong structural constraints, further temperature control measures are needed to reduce the surface tensile stress, so that the hydraulic structures with medium wall thickness meets the temperature control requirements.

For large-volume and large-scale hydraulic structures, such as concrete gravity dam, adding hydration heat inhibitor inhibits the early hydration reaction and slows the heat release, and temperature accumulation will cause the temperature peak to rise, resulting in an increase in the temperature difference between internal and external area, and the surface tensile stress will increase about $7 \%$. Because the hydration reaction is inhibited and the temperature peak is delayed, more compressive stress can be stored in concrete internal area during the temperature rise period, and the final internal tensile stress will be reduced about $30 \%$. For the temperature control of concrete gravity dam, by only adding hydration heat inhibitor, the internal and external tensile stress of concrete will exceed the tensile strength, so other temperature control measures such as arranging cooling water pipe and strengthening surface insulation are still needed.

\section{Data Availability}

The data used to support the findings of this study are available from the corresponding author upon request.

\section{Conflicts of Interest}

The authors declare that there are no conflicts of interest regarding the publication of this paper.

\section{Acknowledgments}

This study was financially supported by the National Natural Science Foundation of China (51679074).

\section{References}

[1] A. B. Hossain and J. Weiss, "Assessing residual stress development and stress relaxation in restrained concrete ring specimens," Cement and Concrete Composites, vol. 26, no. 5, pp. 531-540, 2004.

[2] G. L. Tian and Y. Wang, "Numerical simulation analysis on mass concrete thermal stress," Applied Mechanics and Materials, vol. 204-208, pp. 4396-4399, 2012.

[3] N. Shi, J. Ouyang, R. Zhang, and D. Huang, "Experimental study on early-age crack of mass concrete under the controlled temperature history," Advances in Materials Science and Engineering, vol. 2014, Article ID 671795, 10 pages, 2014.

[4] J.-H. Ha, Y. s. Jung, and Y.-g. Cho, "Thermal crack control in mass concrete structure using an automated curing system," Automation in Construction, vol. 45, pp. 16-24, 2014.

[5] Y. S. Chae, M. H. Lee, B. Su Khil, and H. D. Yun, "Influence of casting temperature on the heat of hydration in mass concrete foundation with ternary cements," Applied Mechanics and Materials, vol. 525, pp. 478-481, 2014.

[6] D. P. Bentz, V. Waller, and F. de Larrard, "Prediction of adiabatic temperature rise in conventional and high-performance concretes using a 3-D microstructural model," Cement and Concrete Research, vol. 28, no. 2, pp. 285-297, 1998.

[7] Y. Bie, S. Qiang, X. Sun, and J. Song, "A new formula to estimate final temperature rise of concrete considering 
ultimate hydration based on equivalent age," Construction and Building Materials, vol. 142, pp. 514-520, 2017.

[8] G. W. Zuo, W. Li, and J. Su, "Temperature control technique and analysis of mass concrete in the pile cap of main pier in yangtze river bridge," Applied Mechanics and Materials, vol. 587-589, pp. 1407-1411, 2014.

[9] Z. Wang, L. Tao, Y. Liu, and J. Yunhui, “Temperature control measures and temperature stress of mass concrete during construction period in high-altitude regions," Advances in Civil Engineering, vol. 2018, Article ID 9249382, 12 pages, 2018.

[10] Y. Huang, "Optimization of temperature-control measures for concrete structures: a case study of the sluice project," Advances in Civil Engineering, vol. 2018, Article ID 4823130, 8 pages, 2018.

[11] C. K. Rankoth, A. Hosoda, and K. Iwama, "Modeling and verification of early age thermal stress in second lining concrete of NATM tunnels," Journal of Advanced Concrete Technology, vol. 15, no. 6, pp. 213-226, 2017.

[12] Y. Liu, Z. H. Wang, and P. Y. Shu, "Temperature control and anti-cracking measures for a high-performance concrete aqueduct," Applied Mechanics and Materials, vol. 405-408, pp. 2739-2742, 2013.

[13] N. P. Mailvaganam and M. R. Rixom, Chemical Admixtures for Concrete, CRC Press, London, UK, 3rd edition, 1999.

[14] R. Mbugua, R. Salim, and J. Ndambuki, "Effect of gum Arabic karroo as a water-reducing admixture in concrete," Materials, vol. 9, no. 2, pp. 80-2, 2016.

[15] J. L. Poole, K. A. Riding, M. C. G. Juenger, K. J. Folliard, and A. K. Schindler, "Effect of chemical admixtures on apparent activation energy of cementitious systems," Journal of Materials in Civil Engineering, vol. 23, no. 12, pp. 1654-1661, 2011.

[16] J.-C. Sun, B.-J. Wang, and W.-Z. Zhao, "Experimental studyon the impact of admixture for concrete heat of hydration andearlyge contractile properties," Pts 1-3, X. D. Zhang, H. N. Li, X. Feng,and Z. Chen, Eds., in Sustainable Development of Urban Infrastructure, Trans Tech Publications Ltd, Guilin, China, Applied Mechanics and Materials, 2013.

[17] H. Zhang, L. Li, W. Wang, and J. Liu, "Effect of temperature rising inhibitor on expansion behavior of cement paste containing expansive agent," Construction and Building Materials, vol. 199, pp. 234-243, 2019.

[18] H. Zhang, X. Liu, P. Feng, L. Li, and W. Wang, "Influence of temperature rising inhibitor on nucleation and growth process during cement hydration," Thermochimica Acta, vol. 681, Article ID 178403, 2019.

[19] Y. Yan, A. Ouzia, C. Yu, J. Liu, and K. L. Scrivener, "Effect of a novel starch-based temperature rise inhibitor on cement hydration and microstructure development," Cement and Concrete Research, vol. 129, Article ID 105961, 2020.

[20] Z. H. U. Bofang, Thermal Stresses and Temperature Control of Mass Concrete, Butterworth-Heinemann, Oxford, UK, 2014.

[21] Y. Huang, G. Liu, S. Huang, R. Rao, and C. Hu, "Experimental and finite element investigations on the temperature field of a massive bridge pier caused by the hydration heat of concrete," Construction \& Building Materials, vol. 192, pp. 240-252, 2018.

[22] P. Li, J. Gao, and X. Zeng, "Analysis of the atmospheric temperature stress on mass concrete by ansys software," in Advances in Civil Engineering, Pts 1-6, J. Y. Zhao, Ed., vol. 3539, ASTM International, West Conshohocken, PA, USA, 2011, Advanced Materials Research.
[23] S. I. Zheng, L. I. Shouyi, P. Chen, and J. Yang, "Development of temperature field calculation program on ansys platform for mass concrete structure," Journal of Yangtze River Scientific Research Institute, vol. 28, no. 9, pp. 53-56, 2011.

[24] N. A. Coelho, L. J. Pedroso, J. H. Silva Rego, and A. N. Alberto, "Use of ansys for thermal analysis in mass concrete," Journal of Advanced Concrete Technology, vol. 8, no. 7, pp. 860-868, 2014.

[25] Y. Wang, E.-b. Pang, H.-c. Zhang, and L. Yang, "Numerical simulation and monitoring of mass concrete wall temperature field," K. Kida, Ed., vol. 262, Wiley Online Library, Hoboken, NJ, USA, 2013, Advanced Materials Research.

[26] L. I. J. hong, S. He, and Q. G. Yuan, "Development of construction technique of large sized aqueduct body," China Rural Water and Hydropower, vol. 10, pp. 61-63, 2005, in Chinese. 